\title{
ULJMSR
}

Journal of Medical and Surgical Research

\section{DIABETES AND THE PROSPECT OF A NATIONAL AND GLOBAL DISASTER}

\author{
Prof. Jamal BELKHADIR
}

Former Chief Medical Officer of the Hospital Ibn Sina

President of the Moroccan League for the Fight against Diabetes

Corresponding Author:

Prof. Jamal BELKHADIR,

President of the Moroccan League for the Fight against Diabetes.

E-mail: jamalbelkhadir@yahoo.fr

ORCID: https://orcid.org/0000-0002-4031-1677

Copyright (C) 2012- 2015 J. Belkhadir. This is an open access article published under Creative Commons Attribution -Non Commercial- No Derives 4.0 International Public License (CC BY-NC-ND). This license allows others to download the articles and share them with others as long as they credit you, but they can't change them in any way or use them commercially.

\section{doi: $10.46327 / \mathrm{msrjg} .1 .000000000000020$}

*****Published in Feb. 2015.

doi url: https://doi.org/10.46327/msrjg.1.000000000000020

Diabetes, obesity with their cardiovascular consequences are now a worldwide epidemic with medical, social and economic devastating and unprecedented. These diseases are no longer limited to "rich countries", and now a growing public health problem in developing countries; where the "Western" dietary pattern spreads and often replaces the traditional and healthy food. To this must be added the profound changes associated with rapid urbanization, changes in social, family and technological advances and comfort. The role of the food industry is highly present in a consumer society living under the influence and pressure of advertising.

Between 1960 and today, barely two generations, the Moroccan food, Maghreb countries and the MENA region has been completely transformed. This phenomenon can be explained by the profound social and economic changes that led to an upheaval in lifestyle during this same period. Indeed, the transition to an abundant supply towards refined foods and sweet, of animal foods and fats plays a major role in the current epidemic of obesity, diabetes and cardiovascular disease, among other non-communicable diseases. According to figures from the International Diabetes Federation, the number of people with diabetes now exceeds 382 million and will reach 595 million in less than 25 years.

About obesity, 1.4 billion people aged 20 and over are overweight. About 3.4 million adults die each year. In addition, $44 \%$ of the burden of diabetes, $23 \%$ of the burden of ischemic heart disease and $7 \%$ to $41 \%$ of the burden of certain cancers are attributable to overweight and obesity. Overall, more than one in ten adults worldwide are obese. To this must be added the new danger that of childhood obesity. About 40 million children under 5 are overweight in 2012. Once considered a problem only in high income countries, overweight and obesity are increasing dramatically in low- and middle-income, primarily urban environment. In developing countries and emerging economies, the prevalence of overweight and obesity in preschoolers over $30 \%$.

In Morocco, diabetes is steadily increasing and it is estimated the number of diabetics to more than 1.8 million. Similarly, the number of overweight or obese is increasing, and well beyond the 3 million Moroccans.

If nothing is done, these new scourges with complications threaten to absorb the benefits of economic progress worldwide. When it comes to disability, alternative health care costs and other factors could triple the already high numbers of WHO. Government budgets across the planet will face immense pressure from the care of people with diabetes, resulting in the payment of disability pensions, compensation, medical and social services costs, and income. In addition, private health insurance and employers will face the rising costs of treating more and more people with diabetes.

Faced with this dramatic picture, can we hope to reverse the situation and fight effectively against the new national and global epidemic?

Yes, according to the International Diabetes Federation and WHO, a healthy lifestyle is the cornerstone of this strategy. Indeed, changes in lifestyle, such as healthy eating and physical activity are effective in delaying and, in many cases, prevent the onset of type 2 diabetes and reduce the risk of complications for patients already. It is estimated that by monitoring the weight of adults, could be reduced by at least $50 \%$ the number of diabetes cases. 
To achieve this goal in our country, changes in individual and collective behavior have to be made quickly! The whole society must be involved and feel concerned. The first health professionals but also policy makers and the private sector must make an effort to reduce the overall risk rate in the population. To do this, the promotion and implementation of environmental measures (in the areas of health, transport, agriculture, finance, etc.) that encourage a healthy lifestyle from childhood are indispensable. All this must be done in close liaison with the ongoing actions and seek to develop an integrated model that takes into account the Moroccan authenticity but also challenges and risks of globalization.

Let us work together to fight against this epidemic that truly represents with the other NCDs the challenge of the 21 st century. 